\title{
A Research on the Project of Digital Comprehensive Capability Platform for Shipbuilding
}

\author{
Nan Ren', Jianyi Liu ${ }^{2}$, Xiang Su ${ }^{3}$, Ping Wang ${ }^{4}$ and Juan Yin ${ }^{5}$ \\ ${ }^{1.3 .4 .5}$ Economic and Management School, Jiangsu University of Science and Technology, \\ Zhenjiang 212003, Jiangsu, P.R. China rennan_hb@sobu.com susoft@jzerp.com \\ Sdwangp1975@sina.com bamhill@163.com \\ ${ }^{2}$ Business Administration School, Jiangsu University, Zhenjiang 212003, Jiangsu, \\ P.R.Chinabjliujianyi@163.com
}

\begin{abstract}
This paper is, centering on the requirement of the modern shipbuilding mode, to study on the project of digital comprehensive capability platform for shipbuilding. The purpose was to realize high integration and collaboration among the functions of design, manufacturing and management in shipbuilding enterprises, and form a high collaborated industry chain with its suppliers and client-industries through such solution project, which includes shipbuilding enterprise innovation development platform, advanced shipbuilding management platform, collaborative business comprehensive management platform, resources supply and demand on industry chain collaboration management platform. As the core competencies of shipbuilding enterprises, a manufacturing resources data standard was also suggested.
\end{abstract}

Keywords: Shiphuilding, Digital comprehensive capability platform, Enterprise Information Systems (EIS), Enterprise management, Enterprise integration

\section{INTRODUCTION}

To implement the modern shipbuilding mode, a total assembly shipbuilding mode featured by middle-products, is the key to the state-of-the art shipbuilding industry. This mode requires a platform to integrate designing, production and business management, and to ensure the concert collaboration among the supply chain of thousands collaborated enterprises.

This article discusses the key elements in building the digital platform.

\section{THE COMPONENTS OF DIGITAL SHIPBUILDING COMPREHENSIVE CAPABILITY PLATFORM}

The total framework of the digital shipbuilding comprehensive capability platform is shown in figure 1.

Please use the following format when citing this chapter:

Ren. N., I.iu, J., Su, X., Wang. P., Yin, J.. 2007. in IFIP International Federation for Information Processing. Volume 254. Research and Practical Issues of Futerprise Information Systems II Volume 1, eds. I. Xu. Tjoa A., Chaudhry S. (Boston: Springer), pp. 487-491. 


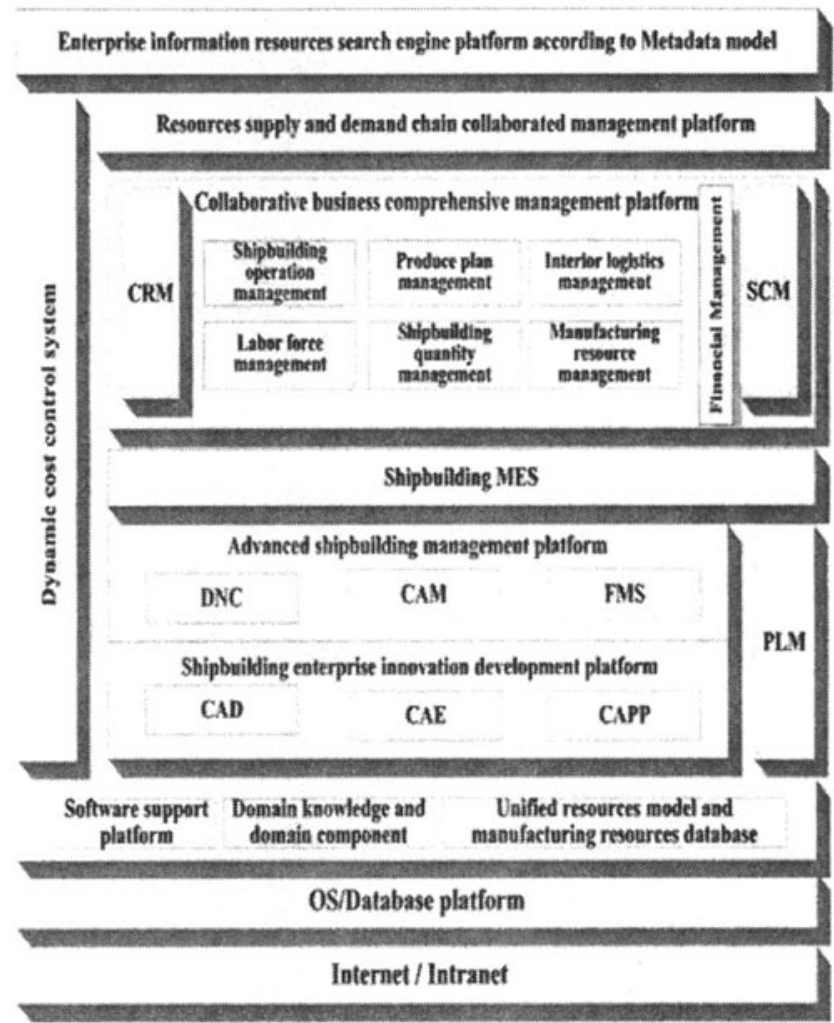

Figure 1. The Structure of Digital Shipbuilding Comprehensive Capability Platform

\subsection{Research and Develop Product Data Code of WBS Standards in the Shipbuilding Business}

Using the WBS (Work Breakdown Structure ) as a guide, all jobs of the whole life cycle of a project or product are decomposed step by step into the mission packets (WOP). According to the craft processes the mission packets (WOP) are subdivided into work orders (W/O). Each WBS unit is an independent part, can be one or many work packets and then is convenient to distribute or outsource missions. The main components of a mission packet (WOP) include the work specialties, labor hours, material information, elements of WBS, diagram paper, the CBS (cost subdivides structure) elements etc. The work order (W/O) mainly includes the work specialties, labor hours, materials, quantity, the construction diagram etc. Integrated system solution should extend the ideology of WBS into workshops areas to get production ability balanced. 


\subsection{Set up the Shipbuilding Design Innovation Development Platform}

Contract design and detailed design are always designed by experienced shipbuilding design institutes, and production design is always done by mature software. So the emphasis for the integrated design is the establishment of the data standard, unification of the resources code system, and management of the technical documents in the designing process, more over, it should be designed as a collaborated working platform for all the production designers, developers and managers.

\subsection{Set up the Integrated Platform of Shipbuilding Production Manufacturing}

To utilize the process data in the complicated dynamic production management system, we should introduce the product process data management (PPDM), which serves as a connecting link in the whole shipbuilding design platform, realizing the integrated $\mathrm{CAD} / \mathrm{CAM}$ upward, and integrating to the complicated dynamic production management downward. Because the EBOM is dynamic and informationincreasing, the integration with PPDM up and down should also be dynamic and information-increasing [1]. Based on the statistics and analysis on actual data, developing engineering plans for similar type of ships will get more and effective foundations by accumulating knowledge and genetic optimized production manufacturing resources [2].

\subsection{Set up the Business Process Collaboration Management Platform of Shipbuilding Enterprises}

Driven by sale management, based on technology and centered by deadline and cost control, the business process collaboration management of shipbuilding includes sale management platform, the reconfigurable and dynamic production plan management system with the ideology of concurrent engineering, quality management platform, and labor force management platform which mainly addresses the problem of who are responsible for the jobs.

\subsection{Set up the Collaborated Resources Management Platform of Shipbuilding Manufacturing Industry Supply Chain}

It is necessary to implement effective control on shipbuilding combining logistics management and target cost management. Given the characteristics of the multicollaboration shipbuilding, the collaborated resources management platform includes materials stock management, supply chain architecture, purchase and manufacture integration, logistics optimization. In the process of BPR, business management and operation procedures are standardized. Meanwhile such platform can provide information about materials preparation and cost on entire project dynamically and 
concurrently, which can help enterprises to realize target cost management.

\subsection{Set up Dynamic Cost Control System of Shipbuilding Manufacturing}

Within the projects, the all-processes cost management includes quoting price, target cost budget, design cost control, purchase cost control, manufacturing process cost control, accounting and checking cost, which is required by the modern shipbuilding mode [3]. This target cost management system combines the pre-control, ongoing control, and post-control, which integrates the cost planning, cost control and cost analysis. As the cost management involves in the whole processes of enterprise manufacturing and management, therefore, the emphasis is to realize the evolution of BOM in the entire PLM, which attaches monitoring and evaluation information to BOM.

\subsection{Set up the Enterprise Information Resources Search Engine Platform according to Metadata Model}

With the shipbuilding industry domain ontology as the meta-model for capturing requirements, the EIS can integrate the knowledge of different levels. Meanwhile, such meta-model can optimize its own structure by analyzing the relationship of the available data [4]. By building the meta-model, we can classify resources, and check them according to the rule of code system, provide users with different defined rights, to access and browse different information or knowledge mining in the enterprise information resources search engine platform. This platform supports the decisionmaking analysis for the active intelligent recommendation.

\subsection{The Support System Structure and the Related Technology}

It is necessary to make sure that the platform can be expanded and reusable and can realize component-businesses, flexible processes, standard interfaces, and professional security. It is based on unified resources model and manufacturing resources database, which includes the metadata model describing the shipbuilding enterprises resources, and provides much more effective technique support for planning similar ships.

\section{CONCLUSIONS}

Establishing a digital comprehensive capability platform to realize the dynamic deadline control and cost control, and to build-up a manufacturing resources data standard reflecting the core competency of a shipbuilding enterprise, can improve the management level of the shipbuilding industry of our nation and make it more stronger and competitive. 
A Research on the Project of Digital Comprehensive Capability Platform for

\section{ACKNOWLEDGEMENTS}

Shipbuilding 491

This research was supported by National Natural Science Foundation of China: Study on Data Model for Large-piece One-of-a-kind Production Enterprise (Grant NO. 70472005).

\section{REFERENCES}

1. X. Su, X. Ning, Y. Pan, and X. Ma, Study on Unification of Informationization Catering to Shipbuilding Enterprises, Shipbuilding of China. Volume 46, Number 4, pp.78-85, (2005).

2. Q. Ling, The Pivot for Informatization of Manufacturing Industry is MES, China Computer (Aug. 9, 2006).

3. Y. Pan and J. Wu, The Cost Control Method in Small-batch Factories, Mie of China. Volume 34, Number 12, pp.23-26, (2005).

4. S. Ge and Y. Pan, Enterprise Information Model for Large-piece one-of-a-kind Production Enterprise (Science Press: Beijing, 2006). 